Mössbauer spectroscopy study of $60 \mathrm{P}_{2} \mathrm{O}_{5}-40 \mathrm{Fe}_{2} \mathrm{O}_{3}$ glass crystallization

Paweł Stoch, Agata Stoch

Abstract. $60 \mathrm{P}_{2} \mathrm{O}_{5}-40 \mathrm{Fe}_{2} \mathrm{O}_{3}$ glass was synthesized and ${ }^{57} \mathrm{Fe}$ Mössbauer spectroscopy study was presented. The main goal of the research was to investigate structural changes of local environment of iron ions during gradual crystallization of the glass. It was observed that some changes were evidenced at temperature of heat treatment higher than $400^{\circ} \mathrm{C}$, above which content of tetrahedrally coordinated $\mathrm{Fe}^{3+}$ was increased in cost of octahedral sites. This led to formation of areas of nucleation of $\alpha-\mathrm{FePO}_{4}$. Crystallization of $\alpha-\mathrm{Fe}_{3}\left(\mathrm{P}_{2} \mathrm{O}_{7}\right)_{2}$ and $\mathrm{Fe}_{2} \mathrm{P}_{2} \mathrm{O}_{7}$ was also observed.

Key words: crystallization $\bullet$ iron phosphate glass $\bullet$ Mössbauer spectroscopy $\bullet$ nuclear waste $\bullet$ waste glass

\section{P. Stoch}

Faculty of Materials Science and Ceramics, AGH - University of Science and Technology, 30 Mickiewicza Ave., 30-059 Kraków, Poland, Tel.: +48 126172465 ,

E-mail: pstoch@agh.edu.pl

\section{A. Stoch}

Institute of Electron Technology Krakow Division, Zablocie 39, 30-701 Kraków, Poland

Received: 18 June 2014

Accepted: 2 November 2014

\section{Introduction}

Iron phosphate glasses are of special interest because of practical and scientific reasons. Phosphate glasses, in general, are characterized by a low-chemical durability and are used as matrix for encapsulation of microelements, which could be leached off in a controlled way to fertilize the soil [1]. On the other hand, iron can significantly increase its water resistance and glasses of composition $60 \mathrm{P}_{2} \mathrm{O}_{5}-40 \mathrm{Fe}_{2} \mathrm{O}_{3}$ have a superior chemical durability, which is even higher than commonly used borosilicate glasses for vitrification of radioactive waste [2, 3]. In waste vitrification technology, one of the very important parameters is homogeneity of the obtained melt without any inclusions of crystal phases, which could lead to segregation of radionuclides, creation of internal stresses and cracks in a vitrified product $[2,3]$. Poor effect of crystallization of $60 \mathrm{P}_{2} \mathrm{O}_{5}$ $-40 \mathrm{Fe}_{2} \mathrm{O}_{3}$ glass is observed above $700^{\circ} \mathrm{C}$ and leads to formation of a glass-ceramic material in which, beside amorphous-phase formation of $\alpha-\mathrm{FePO}_{4}$ and $\mathrm{Fe}_{2} \mathrm{P}_{2} \mathrm{O}_{7}$, crystal phases is present [4]. The $\mathrm{FePO}_{4}$ is, in the case of iron phosphate glasses, the structural analogue of $\mathrm{SiO}_{2}$ (a main building block of silicate glasses), which is characteristic of similar phase transition from $\alpha$-quartz to $\beta$-quartz at $700^{\circ} \mathrm{C}$ with alternate corner sharing of both $\left[\mathrm{FeO}_{4}\right]^{-}$and $\left[\mathrm{PO}_{4}\right]^{+}$ tetrahedra [5].

Therefore, the aim of the paper was to observe changes of local iron environment during gradual crystallization of the $60 \mathrm{P}_{2} \mathrm{O}_{5}-40 \mathrm{Fe}_{2} \mathrm{O}_{3}$ glass. 


\section{Experiment}

Glass was prepared from chemical pure $\mathrm{NH}_{4} \mathrm{H}_{2} \mathrm{PO}_{4}$ and $\mathrm{Fe}_{2} \mathrm{O}_{3}$. Batches to produce $100 \mathrm{~g}$ of the $60 \mathrm{P}_{2} \mathrm{O}_{5}-40 \mathrm{Fe}_{2} \mathrm{O}_{3}$ glass were melted for $2 \mathrm{~h}$ at $1350^{\circ} \mathrm{C}$ in $\mathrm{Al}_{2} \mathrm{O}_{3}$ crucible in an electric furnace with the furnace atmosphere as close to natural as possible. The melt was vitrified by casting onto steel plate. The obtained sample was crushed and the pieces were heat treated at temperatures from $350^{\circ} \mathrm{C}$ to $700^{\circ} \mathrm{C}$ with step of $50^{\circ} \mathrm{C}$ degrees by $24 \mathrm{~h}$.

For Mössbauer analysis, the heat-treated samples were powdered in an agate mortar. Spectrum was collected at room temperature using a $25 \mathrm{mCi}{ }^{57} \mathrm{Co}$ source embedded in $\mathrm{Rh}$ matrix. A velocity range $\pm 4 \mathrm{~mm} / \mathrm{s}$ was used and spectrometer was calibrated using $\alpha$-Fe foil.

In the case of amorphous materials like glasses, the interpretation of a Mössbauer spectrum is not so unambiguous like for crystalline compounds. In crystalline compounds, every crystallographic iron site can be observed as one component of the spectrum. In disordered amorphous materials, however, there are many different local iron environments and every one of them is described by a different set of hyperfine interaction parameters. As a consequence, the collected spectrum is a composition of many individual components. In oxide glasses, every iron cation has only oxygen anions in the first neighborhood, but deviations in coordination or iron-oxygen distance, etc. should reflect the observed effect and the hyperfine interaction parameters. In the case of amorphous materials, one method for processing the spectra is an Extended Voigtian Based analysis $(\mathrm{xVBF})$, which has been described in detail elsewhere $[6,7]$. In this method, every iron atom site is given by a Gaussian distribution of an independent isomer shift and quadrupole splitting due to some randomness in the local environment of iron. Effectiveness of the method in fitting of Mössbauer spectra of iron phosphate glasses was previously proved $[8,9]$.

\section{Results and discussion}

An exemplary Mössbauer spectrum of the glass sample heated at $500^{\circ} \mathrm{C}$ is presented in Fig. 1 and is typical for iron phosphate glass $[8,9]$. The analogous spectra were obtained for all studied materials and were deconvoluted using three different iron sites, which represent tetrahedrally coordinated ${ }^{\mathrm{IV}} \mathrm{Fe}^{3+}$, octahedrally coordinated ${ }^{\mathrm{VI}} \mathrm{Fe}^{3+}$ and $\mathrm{Fe}^{2+}$ that are assumed to exist in various coordination environments [9]. The fitted hyperfine interaction parameters for the sample heated at $500^{\circ} \mathrm{C}$ are presented in Table 1, namely: A - area of the site, IS - isomer shift,

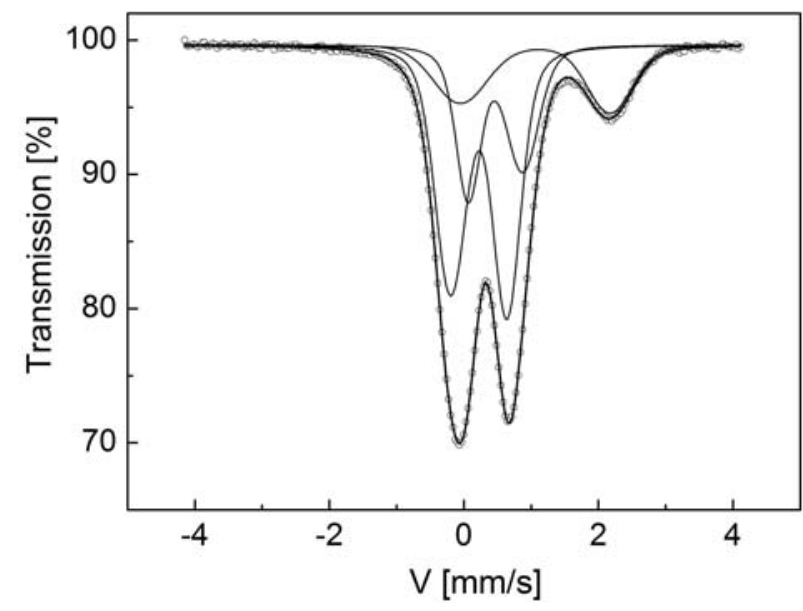

Fig. 1. ${ }^{57} \mathrm{Fe}$ Mössbauer spectra of the $60 \mathrm{P}_{2} \mathrm{O}_{5}-40 \mathrm{Fe}_{2} \mathrm{O}_{3}$ glass heat treated at $500^{\circ} \mathrm{C}$.

QS - quadrupole splitting, $\sigma_{\mathrm{IS}}$ and $\sigma_{\mathrm{QS}}$ - Gaussian widths of the distribution of isomer shift and quadrupole splitting, respectively, and $\rho$ (IS, QS) - correlation parameter between IS and QS.

Share percentages of the components independent of sample heating temperature are presented in Fig. 2. The $\mathrm{Fe}^{2+}$ concentration was approximately $20 \%$ and was almost constant. The rest of iron ions were present as $\mathrm{Fe}^{3+}$ with almost equal population between 4 and 6 coordinated sites for samples heated at the lowest temperature. This gave mean coordination number of $\mathrm{Fe}^{3+}$ equal 5, which was previously observed [5]. At temperature above $400^{\circ} \mathrm{C}$ is evidenced gradual increase of tetrahedrally coordinated $\mathrm{Fe}^{3+}$ in cost of ${ }^{\mathrm{VI}} \mathrm{Fe}^{3+}$, which is probably due to increase of local order of the both sites and formation of regions, which are enriched in ${ }^{\mathrm{IV}} \mathrm{Fe}^{3+}$. This effect could be related to nucleation of $\alpha-\mathrm{FePO}_{4}$ crystallization.

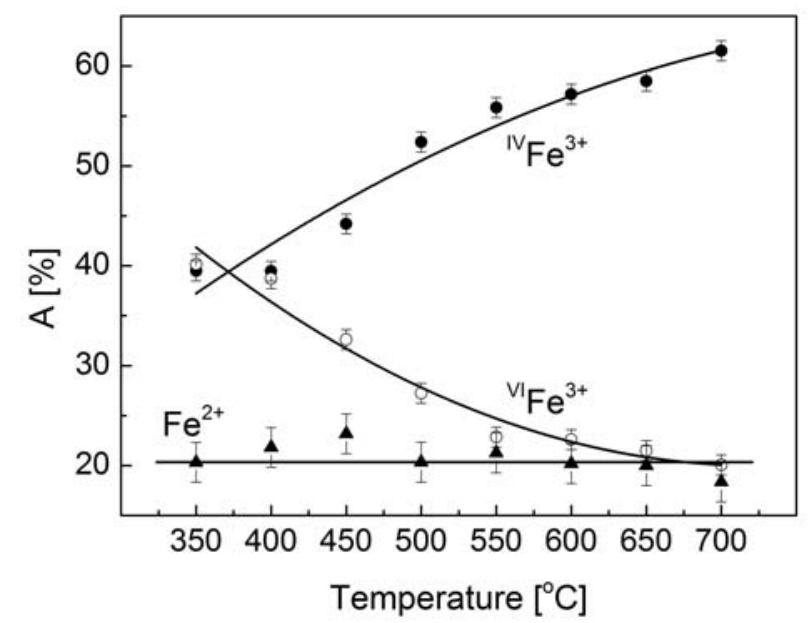

Fig. 2. Share percentage of different iron sites independent of the sample heating temperature.

Table. 1. The hyperfine interaction parameters of $60 \mathrm{P}_{2} \mathrm{O}_{5}-40 \mathrm{Fe}_{2} \mathrm{O}_{3}$ glass heated at $500^{\circ} \mathrm{C}$

\begin{tabular}{|c|c|c|c|c|c|c|}
\hline Site & $\begin{array}{c}\mathrm{A} \\
{[\%]}\end{array}$ & $\begin{array}{c}\text { IS } \\
{[\mathrm{mm} / \mathrm{s}]}\end{array}$ & $\begin{array}{c}\mathrm{QS} \\
{[\mathrm{mm} / \mathrm{s}]}\end{array}$ & $\begin{array}{c}\sigma_{\mathrm{IS}} \\
{[\mathrm{mm} / \mathrm{s}]}\end{array}$ & $\begin{array}{c}\sigma_{\mathrm{QS}} \\
{[\mathrm{mm} / \mathrm{s}]}\end{array}$ & $\rho(\mathrm{IS}, \mathrm{QS})$ \\
\hline${ }^{\mathrm{iv}} \mathrm{Fe}^{3+}$ & 52.4 & $0.320(5)$ & $0.84(6)$ & 0.128 & 0.24 & -0.140 \\
\hline${ }^{\mathrm{vI}} \mathrm{Fe}^{3+}$ & 27.3 & $0.580(5)$ & $0.80(4)$ & 0.129 & 0.21 & 0.336 \\
\hline $\mathrm{Fe}^{2+}$ & 20.3 & $1.170(10)$ & $2.17(1)$ & 0.230 & 0.47 & -0.193 \\
\hline
\end{tabular}




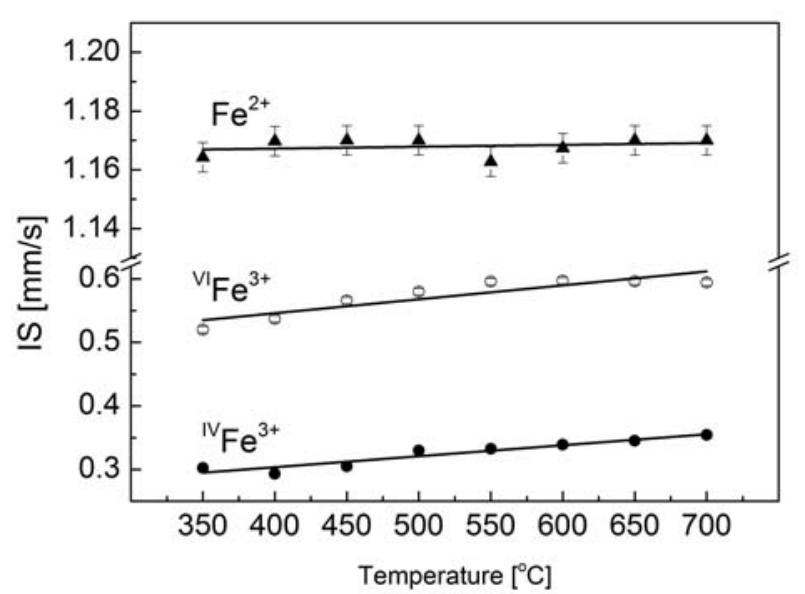

Fig. 3. The mean isomer shift of the iron sites independent of the sample heating temperature.

The mean isomer shift of the sites is presented in Fig. 3. The ${ }^{\mathrm{IV}} \mathrm{Fe}^{3+}$ isomer shift was slightly increased from 0.29 to $0.33 \mathrm{~mm} / \mathrm{s}$. Similar behavior was observed for ${ }^{\mathrm{VI}} \mathrm{Fe}^{3+}$ and, as would be expected, the IS values were higher and ranged between 0.5 and $0.6 \mathrm{~mm} / \mathrm{s}$. The IS value of $\mathrm{Fe}^{2+}$ was almost constant and took approximately value of $1.17 \mathrm{~mm} / \mathrm{s}$.

The mean quadrupole splits of the sites are presented in Fig. 4. The QS values of $\mathrm{Fe}^{2+}$ were almost independent of the sample heating temperature. In case of the tetrahedrally coordinated $\mathrm{Fe}^{3+}$ sites, the QS parameter was decreasing at low-heating temperatures up to $500^{\circ} \mathrm{C}$, an opposite effect was observed for octahedral iron sites. Both parameters were almost constant for the higher heating temperatures.

According to the previous results of $60 \mathrm{P}_{2} \mathrm{O}_{5^{-}}$ $-40 \mathrm{Fe}_{2} \mathrm{O}_{3}$ glass crystallization studies, it was observed that crystallization started above $700^{\circ} \mathrm{C}$ with a very poor effect of crystallization on DSC curve. It was found that the obtained material was glass-ceramic and the main crystal phases based on X-ray diffraction analysis were identified as $\alpha-\mathrm{FePO}_{4}$ and $\mathrm{Fe}_{2} \mathrm{P}_{2} \mathrm{O}_{7}$ [4]. In $\alpha-\mathrm{FePO}_{4}$ crystal structure, there is one tetrahedral $\mathrm{Fe}^{3+}$ iron site and IS value of this site is in the range of $0.27-0.32 \mathrm{~mm} / \mathrm{s}[10,11]$, which is in accordance with the values obtained in the present studies. In case of $\mathrm{Fe}_{2} \mathrm{P}_{2} \mathrm{O}_{7}$ phase, there

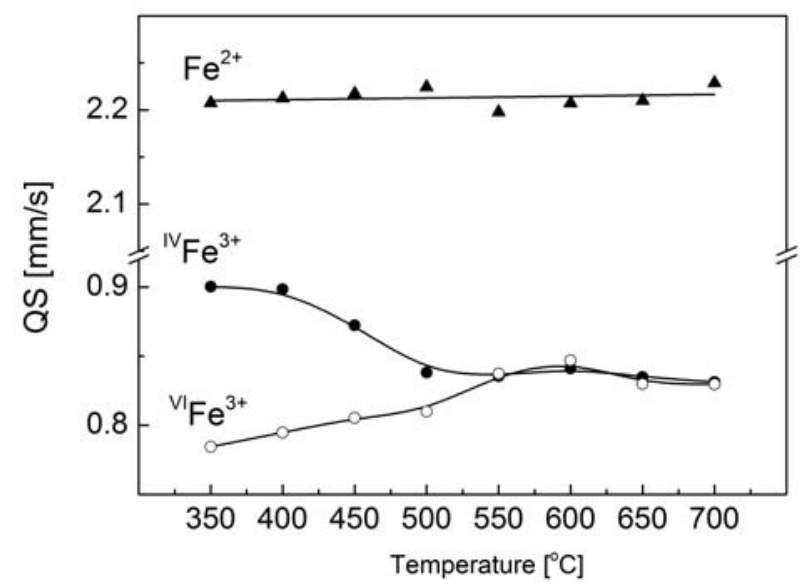

Fig. 4. The mean quadrupole splitting of the iron sites independent of the sample heating temperature. are two $\mathrm{Fe}^{2+}$ iron sites characterized by similar IS values approximately $1.2 \mathrm{~mm} / \mathrm{s}$ and slightly different QS [12]. This IS value is close to the $1.17 \mathrm{~mm} / \mathrm{s}$, which was obtained in the present paper. On the other hand, the studied material part of $\mathrm{Fe}^{3+}$ iron was situated in octahedral coordination with high IS values above $0.5 \mathrm{~mm} / \mathrm{s}$. These ions could not be assigned to $\alpha-\mathrm{FePO}_{4}$ or $\mathrm{Fe}_{2} \mathrm{P}_{2} \mathrm{O}_{7}$ phase. The IS values of approximately $0.5 \mathrm{~mm} / \mathrm{s}$ were previously reported for six coordinated $\mathrm{Fe}^{3+}$ iron in $\alpha-\mathrm{Fe}_{3}\left(\mathrm{P}_{2} \mathrm{O}_{7}\right)_{2}$ phase where beside two $\mathrm{Fe}^{3+}$ cations existed one $\mathrm{Fe}^{2+}$ per formulae characterized by IS about $1.2 \mathrm{~mm} / \mathrm{s}$ [11]. Taking all into account, it could be concluded that approximately: $60 \%$ of iron was present in $\alpha-\mathrm{FePO}_{4}$, $30 \%$ in $\alpha-\mathrm{Fe}_{3}\left(\mathrm{P}_{2} \mathrm{O}_{7}\right)_{2}$, and $10 \%$ only in $\mathrm{Fe}_{2} \mathrm{P}_{2} \mathrm{O}_{7}$ crystal phase after crystallization process.

\section{Conclusions}

The ${ }^{57} \mathrm{Fe}$ Mössbauer effect spectrum of $60 \mathrm{P}_{2} \mathrm{O}_{5^{-}}$ $-40 \mathrm{Fe}_{2} \mathrm{O}_{3}$ sample was composed of three different iron environments. In the glass, approximately $20 \%$ of iron ions were present as $\mathrm{Fe}^{2+}$ in octahedral environment in which they could be classified as glass network modifiers. The rest of iron ions were present as $\mathrm{Fe}^{3+}$ in octa- and tetrahedral coordination in which they were glass network modifier and former, respectively. Heat treatment of the glass did not significantly change the local neighborhood of ferrous iron. Much bigger differences were observed in case of ferric iron. During heat treatment procedure, gradually part of octahedrally coordinated iron were transformed into tetrahedrally. This led to formation of areas enriched in four-fold coordinated $\mathrm{Fe}^{3+}$ and nucleating crystallization of $\alpha-\mathrm{FePO}_{4}$, which is the main crystal phase in crystallize sample beside which formation of $\alpha-\mathrm{Fe}_{3}\left(\mathrm{P}_{2} \mathrm{O}_{7}\right)_{2}, \mathrm{Fe}_{2} \mathrm{P}_{2} \mathrm{O}_{7}$ was also observed.

Acknowledgments. The work was supported partially by the National Science Centre of Poland project no. N N507 235740 and partially by the National Centre for Research and Development of Poland as a part of strategic research project "Technologies supporting development of safe nuclear energy".

\section{References}

1. Wacławska, I., \& Szumera, M. (2010). Thermal behaviour of Fe-doped silicate-phosphate glasses. J. Therm. Anal. Calorim., 101(2), 423-427. DOI: 10.1007/s10973-010-0798-5.

2. Donald, W. (2007). Immobilisation of radioactive and non-radioactive wastes in glass-based systems: an overview. Glass Technol.: Eur. J. Glass Sci. Technol. Part A, 48(4), 155-163.

3. Ojovan, M. I., \& Lee, W. E. (2005). An introduction to nuclear waste immobilisation. Oxford, UK: Elsevier Science. DOI: 10.1016/B978-008044462-8.

4. Stoch, P., Ciecinska, M., \& Stoch, A. (2014). Thermal properties of phosphate glasses for salt waste immobilization. J. Therm. Anal. Calorim., 117(1), 177-204. DOI: $10.1007 / \mathrm{s} 10973-014-3698-2$. 
5. Wright, A. C., Sinclair, R. N., Shaw, J. L., Haworth, R., Marasinghe, G., Day, D. E., Bingham, P. A., Forder, S. D., Cuello, G. J., \& Fischer, H. E. (2012). The atomic and magnetic structure and dynamics of iron phosphate glasses. Phys. Chem. Glasses: Eur. J. Glass Sci. Technol. B, 53(6), 227-244.

6. Wivel, C., \& Mørup, S. (1981). Improved computational procedure for evaluation of overlapping hyperfine parameter distributions in Mössbauer spectra. J. Phys. E-Sci. Instrum., 14(5), 605-610. DOI: $10.1088 / 0022-3735 / 14 / 5 / 018$.

7. Alberto, H. V., Pinto da Cunha, J. L., Mysen, B. O., Gil, J. M., \& Ayres de Campos, N. (1996). Analysis of Mössbauer spectra of silicate glass using a two-dimensional Gaussian distribution of hyperfine parameters. J. Non-Cryst. Solids, 194(1), 48-57. DOI: 10.1016/0022-3093(95)00463-7.

8. Stoch, P., Ciecinska, M., Zachariasz, P., Suwalski, J., Górski, L., \& Wójcik, T. (2013). Mössbauer spectroscopy study of $60 \mathrm{P}_{2} \mathrm{O}_{5}-40 \mathrm{Fe}_{2} \mathrm{O}_{3}$ glass. Nukleonika, 58(1), 63-66.
9. Stoch, P., Szczerba, W., Bodnar, W., Ciecińska, M., Stoch, A., \& Burkel, E. (2014). Structural properties of iron-phosphate glasses: spectroscopic studies and ab initio simulations. Phys. Chem. Chem. Phys., 16, 19917-19927. DOI: 10.1039/C4CP03113J.

10. Millet, J. M., Verley, C., Forissier, M., Bussiere, P., \& Verdine, J. C. (1989). Mössbauer spectroscopic study of iron phosphate catalysts used in selective oxidation. Hyperfine Interact., 46(1), 619-628. DOI: 10.1007/ BF02398251.

11. Khan, F. B., Bharuth-Ram, K., \& Friedrich, H. B. (2010). Phase transformations of the $\mathrm{FePO}_{4}$ catalyst in the oxidative dehydrogenation to form an alkyl methacrylate. Hyperfine Interact., 197(1/3), 317-323. DOI 10.1007/s10751-010-0254-8.

12. Ericsson, T., Nord, A. G., Ahmed, M. M. O., Gismelseed, A., \& Khangi, F. (1990). $\mathrm{Fe}_{2} \mathrm{P}_{2} \mathrm{O}_{7}$ and $\mathrm{Fe}_{2} \mathrm{P}_{4} \mathrm{O}_{12}$ studied between 5-800 K. Hyperfine Interact., 57(1/4), 2179-2186. DOI: 10.1007/BF02405783. 